\title{
Médiévales
}

Langues, Textes, Histoire

54 | printemps 2008

Frères et sœurs

Ralph E. GIESEY, Le Rôle méconnu de la loi salique. La succession royale (XIV ${ }^{e}-\mathrm{XVI}{ }^{e}$ siècles), F. Regnot trad., avant-propos F. Cosandey, Paris, Les Belles Lettres, 2007 (Histoire), 396 p., 4 pl., bibliogr., index.

\section{Anne-Hélène Allirot}

\section{(2) OpenEdition}

\section{Édition électronique}

URL : https://journals.openedition.org/medievales/5253

DOI : 10.4000/medievales.5253

ISSN : $1777-5892$

Éditeur

Presses universitaires de Vincennes

\section{Édition imprimée}

Date de publication : 1 juin 2008

Pagination : 157-158

ISBN : 978-2-84292-217-7

ISSN : 0751-2708

\section{Référence électronique}

Anne-Hélène Allirot, «Ralph E. GIESEY, Le Rôle méconnu de la loi salique. La succession royale (XIve-xvie siècles), F. Regnot trad., avant-propos F. Cosandey, Paris, Les Belles Lettres, 2007 (Histoire), 396 p., 4 pl., bibliogr., index. », Médiévales [En ligne], 54 I printemps 2008, mis en ligne le 23 octobre 2008, consulté le 23 avril 2022. URL : http://journals.openedition.org/medievales/5253 ; DOI : https:// doi.org/10.4000/medievales.5253

Ce document a été généré automatiquement le 23 avril 2022

Tous droits réservés 


\title{
Ralph E. GIESEY, Le Rôle méconnu de la loi salique. La succession royale (XIV ${ }^{e}$ $X V I^{e}$ siècles), F. Regnot trad., avant- propos F. Cosandey, Paris, Les Belles Lettres, 2007 (Histoire), 396 p., 4 pl., bibliogr., index.
}

\author{
Anne-Hélène Allirot
}

1 Dans ce nouvel ouvrage, Ralph E. Giesey nous convie à un réexamen minutieux de l'histoire de la très fameuse loi salique, qui a déjà fait couler beaucoup d'encre. L'histoire de l'interprétation de cette loi est ici résolument dissociée de celle de l'exclusion des femmes du trône, qui n'est pas abordée en termes de sexe ou de genre dans les sources du XIV ${ }^{\mathrm{e}}$ siècle. Il s'agit davantage de montrer comment l'argument est manipulé alternativement par Français et Anglais dans un contexte de conflit successoral et politique très particulier. En cela, l'étude vient prolonger et compléter celle de Colette Beaune, qui s'intéressait à la légende et au mythe politique construit autour de cette loi aux deux derniers siècles du Moyen Âge ${ }^{1}$.

2 La volonté de R. E. Giesey est de revenir aux sources et de laisser de côté une historiographie particulièrement pléthorique. Il en résulte donc une analyse extrêmement érudite, précise et néanmoins très claire, qui renouvelle en de nombreux points notre connaissance de la pensée politique de la fin du Moyen Âge. Ainsi la redécouverte de la loi salique ne doit-elle plus être située au XIV ${ }^{\mathrm{e}}$ siècle mais vers 1240 , sous la plume de Jacopo d'Ardizzone, juriste italien auteur d'un long commentaire sur le droit féodal, la Summa feudorum.

3 La spécificité bien française qui consiste à refuser le trône aux femmes ne peut s'expliquer simplement par l'expression d'une misogynie particulière. L'exclusion des filles des derniers Capétiens s'explique d'abord par le contexte de 1316 puis de 1328. 
L'adultère de Marguerite de Bourgogne a certainement pesé bien plus défavorablement sur Jeanne de France que le simple fait qu'elle soit une fille. En 1328, les débats sur la légitimité de Philippe de Valois sont très complexes, comme le montre la Continuation de Nangis. L'essentiel pour l'assemblée des barons est alors de ne pas se soumettre à un souverain étranger.

4 Entre 1337 et 1340, la revendication d'Édouard III se précise pour porter non sur la question d'une éventuelle souveraineté féminine, mais sur la possibilité de faire « pont et planche", de transmettre le trône à son fils. Les Anglais ne contestaient pas la validité de l'argument pour l'exclusion des femmes; pour eux, en revanche, la loi salique ne contenait aucun principe réglant le cas des fils de ces femmes. Ces précisions peuvent être mises en lumière grâce au "dossier juridique » anglais de la Conférence d'Avignon, qui se déroule en 1344. Elles sont ensuite volontairement oubliées par les Grandes Chroniques de France. La loi salique ne fait son apparition dans le débat côté français qu'en 1358 avec Richard Lescot. Mais il ne s'agissait pas alors d'une si grande redécouverte. Les juristes du temps pouvaient en avoir connaissance à travers les commentaires de Jacopo d'Ardizzone.

5 À partir de ce point, l'auteur s'attache à l'analyse de la place de la loi salique dans les écrits juridiques touchant au droit successoral, et cela de la fin du xive siècle jusqu'à l'époque révolutionnaire. La progression est extrêmement méthodique, avec l'examen auteur par auteur et terme par terme des sources envisagées. De Jean de Montreuil à Robert Gaguin, la loi salique devient progressivement l'argument central du débat de 1328 , pour dire désormais que seuls peuvent succéder les « roys du sexe virille seullement yssus des roys masles ». Cette légende définitivement appliquée à l'accession au trône des Valois va ensuite servir également à celle des Bourbons en 1589. En effet, c'est encore au titre de la loi salique, qui impose une définition très particulière de la notion de prince du sang, que le droit d'un parent mâle aussi éloigné qu'Henri de Navarre peut être accepté. Il faut attendre le xVIII ${ }^{\mathrm{e}}$ siècle pour que certains esprits éclairés tels Montesquieu et Voltaire mettent en doute la présentation classique du débat de 1328. Le principe de la double exclusion des femmes et de leur descendance dans la succession royale est encore clairement énoncé dans l'article 4 de la Constitution de 1791.

6 Deux textes essentiels sont présentés en appendice : les convenances du 17 juillet 1316 entre le régent Philippe et Eudes de Bourgogne ainsi que la version des événements de 1328 donnée par la Continuation de Nangis. Le livre est doté de notes très fournies ainsi que d'une belle bibliographie, d'un index et d'un petit dossier iconographique. L'invalidation de certains titres de la bibliographie, signalés par une astérisque, aurait pu donner lieu à quelques remarques ponctuelles plus détaillées. Mais c'est aussi le résultat de la démarche de l'auteur, désirant éviter le débat historiographique pour recentrer son propos sur le sujet.

7 Le Rôle méconnu de la loi salique procède donc à une utile et souhaitable clarification sur un thème très dense et dont les implications politiques sont si profondes aux époques médiévales et modernes. Par l'apport au dossier de sources méconnues et le caractère systématique de la démonstration, R. E. Giesey fait une brillante synthèse de l'histoire d'une manipulation: celle d'un simple article du code des Francs Saliens devenu loi fondamentale de la succession royale de France. 


\section{NOTES}

1. C. BEAUNE, Naissance de la nation France, Paris, 1985. 